\title{
Single nucleotide polymorphism of transforming growth factor- $\beta 1$ and interleukin-6 as risk factors for ovarian cancer
}

\author{
AMIRA BEN AHMED ${ }^{l}$, SABRINA ZIDI ${ }^{l}$, WASSIM ALMAWI', EZZEDDINE GHAZOUANI ${ }^{3}$, \\ AMEL MEZLINI ${ }^{4}$, BESMA YACOUBI LOUESLATI ${ }^{1}$, MOUNA STAYOUSSEF ${ }^{l}$ \\ 'Department of Biology, Faculty of Sciences of Tunis, Laboratory of Mycology, Pathologies and Biomarkers: LR16ES05, El Manar \\ University, Tunis, Tunisia \\ ${ }^{2}$ College of Health Sciences, Abu Dhabi University, United Arab Emirates \\ ${ }^{3}$ Laboratory of Immunology, Military Hospital of Tunis, Tunis, Tunisia \\ ${ }^{4}$ Salah Azeiz Oncology Institute, Tunis, Tunisia
}

\begin{abstract}
Introduction: We investigated the association between common variants in TGF- $\beta 1, I L-6$ and the risk of ovarian cancer $(O C)$ in Tunisian patients and control women.

Material, methods and results: Study subjects comprised 71 OC cases and 74 control women. Genotyping of TGF- $\beta 1$ and IL-6 SNPs was done by real-time PCR. No differences were noted in the minor allele frequencies of the three TGF- $\beta 1$ SNPs between OC patients and controls. However, marked differences in the distribution of TGF- $\beta 1$ rs 1800469 genotypes were seen between OC cases and controls ( $p<0.001)$, with TGF- $\beta 1$ rs 1800469 heterozygous $(C / T)$ genotype being negatively associated with OC $($ OR $[95 \% \mathrm{CI}]=0.24$ [0.15-0.58]). The allelic and genotypic distributions at IL-6 polymorphisms showed a positive association between minor allele $(G)$ at IL-6 rs 1880242 variant $(p=0.0275$; $R[95 \% C I]=1.88$ [1.03-3.46]) and the occurrence of OC. In fact, the presence of $T$ allele $[G / T+T / T]$ decrease the risk of OC $(p=0.021 ;$ OR $[95 \% C I]=0.38$ [0.17-0.88]). In addition, the Haploview analysis demonstrated high linkage disequilibrium $(L D)$ between IL-6 SNPs and eight-locus haplotype analysis identified that GGAGGGGA and GGAGGGTA haplotypes are positively associated with OC risk. A negative association was shown between IL-6 haplotype (TGGGCCTA) and OC occurrence.

Conclusions: Our results suggest that TGF- $\beta 1$ rs 1800469, IL-6 rs 1880242 variants and IL-6 haplotype (TGGGCCTA) have protective roles of OC risk. IL-6 haplotypes (GGAGGGGA and GGAGGGTA) increase OC susceptibility among Tunisian women.
\end{abstract}

Key words: TGF- $\beta 1, I L-6$, gene polymorphism, ovarian cancer, haplotypes, Tunisian women.

(Cent Eur J Immunol 2020; 45 (3): 267-275)

\section{Introduction}

Ovarian cancer (OC) is one of the most common cancers in women worldwide, and a leading cause of death among gynecological malignancies [1]. The incidence of OC among Tunisian women was approximately 4/100,000, with an estimated 93 new cases diagnosed annually [2]. The pathogenesis of OC is not well characterized. In fact, most patients at diagnosis present with advanced stage of disease, and its treatment is refractory to chemotherapy and surgery [3]. The lack of available sensitive and specific screening tests, along with the identification of predictive and prognostic factors, contributes to the aggravation of OC $[4,5]$.
It has been established that an inflammatory reaction is the underlying cause in the development of many types of cancers [6]. Molecular mechanisms causing inflammation-associated cancer include DNA damage disruption of immune response and alternation of the tumor microenvironment, which are all closely related to the disequilibrium of inflammatory cytokines [7, 8].

In this context, few studies have focused on identifying novel biomarkers associated with OC susceptibility, which in turn may facilitate diagnosis, and possibly clinical management [9-11]. Moreover, previous studies have shown that the growth and progression of OC result from a state

Correspondence: Amira Ben Ahmed, PhD, Department of Biology, Faculty of Sciences of Tunis, Laboratory of Mycology, Pathologies and Biomarkers, LR16ES05, El Manar University, 1092 Tunis, Tunisia, e-mail: amirabenahmed@ ymail.com Submitted: 6.09.2017; Accepted: 2.01.2018 
of immunosuppression, which facilitates tumor outgrowth protecting tumor from immune system controlled by cytokines $[12,13]$. Given their role in initiating and sustaining immunologic and inflammatory processes, a strong correlation between chronic inflammation, cytokine expression, and OC development have been reported [14, 15].

Transforming growth factor $\beta$ (TGF- $\beta 1$ ) is a multi-functional anti-inflammatory cytokine involved in the control of cell cycle and plays a role in carcinogenesis through regulating cellular growth, differentiation, adhesion, migration, and apoptosis [16, 17].

TGF- $\beta 1$ reportedly affects early stage of cancer and promotes growth of cancerous cells in later stage [18]. The immunosuppressive role of TGF- $\beta 1$ correlates with its overexpression in later stages of cancer and is dependent on its level of expression by DNA variation in its promoter or regulatory sequences $[19,20]$. The TGF- $\beta 1$ gene is located on chromosome 19 , and several polymorphic variants in the promoter region of TGF- $\beta 1$ gene have been shown to cooperate in modulating transcription factor binding and with the development of OC [21, 22]. Despite the importance of TGF- $\beta 1$ in carcinogenesis, few studies evaluated the association of TGF- $\beta 1$ gene polymorphisms and the risk of OC [22-25].

Interleukin 6 (IL-6), in contrast, is a pro-inflammatory cytokine, with a critical role in inhibition of apoptosis, stimulation of cellular proliferation and angiogenesis, enhancing the invasive and metastatic potential of several cancers [26]. The human IL-6 gene is mapped to chromosome 7p21-24, composed of four introns and five exons, with an upstream promoter containing 303bp [27]. Previous studies demonstrated the involvement of this cytokine in different physiological and pathophysiological processes, such as bone metabolism, synthesis of CRP, and carcinogenesis progression [28, 29].

The IL-6 polymorphism has been regarded as a crucial modulator in pathogenesis of various types of cancer [30-34]. However, allelic distributions of various polymorphisms in IL-6 gene could vary geographically and ethnically, thus leading to discordant findings between these polymorphisms and cancer risk. With respect to the gynecological cancers, it has been reported that increased IL-6 protein levels are associated with malignant ovarian tumors, endometriosis, and cervical cancer $[35,36]$. Therefore, in vitro studies have demonstrated that various ovarian carcinoma cell lines produce IL-6, which is thought to be involved in ovarian carcinogenesis by mediating host immune responses to the disease [29, 37, 38].

The purpose of this pilot study was to investigate the contribution of TGF- $\beta 1$ common variants (rs1800470, rs1800472, and rs1800469) and IL-6 polymorphisms (rs1880242, rs2069827, rs1800797 rs1800796, rs1800795, rs1474348, rs1474347, and rs2069845) to OC susceptibility among Tunisian population.

\section{Material and methods}

\section{Study subjects}

This case-control study was performed between 2012 and 2013 at Salah Azeiz Oncology Institute (SAI), Tunis, Tunisia. Study subjects consisted of 71 patients with histologically confirmed OC and 74 age-matched healthy controls, with no malignancy, drug allergy, hypertension, diabetes, or cardiovascular disease. Clinical data was collected through self-reported questionnaires, and tumor staging was evaluated according to the International Federation of Gynecology and Obstetrics (FIGO) classification (www.figo.org). Study subjects were from North Tunisia, and all women signed an informed consent to participate in the study. The study was approved by the local ethic committee of Salah Azeiz Oncology Institute.

\section{DNA extraction}

Blood samples were taken from all participants using EDTA-containing tube for total genomic DNA extraction shortly before radiation therapy or chemotherapy. Genomic DNA was extracted using QIAamp DNA blood mini kit, according to manufacturer's instruction (Qiagen $\mathrm{GmbH}$, Hilden, Germany).

\section{Genotyping of TGF- $\beta 1$ and IL-6}

SNPs in TGF- $\beta 1$ and IL-6 genes were selected, based on minor allele frequency (MAF) of $>5 \%$ in Caucasians. TGF- $\beta 1$ (rs1800470, rs1800472, and rs1800469) and IL-6 (rs1880242, rs2069827, rs1800797 rs1800796, rs1800795, rs1474348, rs1474347, and rs2069845) genotyping was performed by allelic (VIC- and FAM-labeled) discrimination method. TaqMan assays, as assay-on-demand, were ordered from Applied Biosystems (Foster City, CA, USA). The reaction was performed in a $6 \mu$ l volume on StepOne/ StepOne Plus real-time PCR systems, according to manufacturer's instructions (Applied Biosystems, Foster City, CA, USA). Replicate blinded quality control samples were included to assess the reproducibility of genotyping reaction, with concordance of $>99 \%$. Additional quality control measures with direct DNA re-sequencing of patients $(n=40)$ and controls $(n=40)$ specimens (ABI 3130_1 Genetic Analyzer; Applied Biosystems) were applied. A genotyping call rate exceeded $99 \%$, with no significant differences between cases and control samples.

\section{Statistical analysis}

Statistical analysis was performed on SPSS v. 21.0 (SPSS Inc., Chicago, IL, USA). Data was expressed as percentages of total (categorical variables) or as mean \pm SD (continuous variables). Student's $t$-test was used to determine differences in means, and Pearson-V2 or Fisher's exact tests were used to assess inter-group significance. 
Allele frequencies were calculated by the gene-counting method, and each polymorphism was tested for Hardy-Weinberg equilibrium with c, goodness-of-fit test using SNPStats software (http://bioinfo.iconcologia.net/ snpstats). LD analysis and haplotypes reconstruction was performed with Haploview 4.1 (http://www.broad.mit.edu/ $\mathrm{mpg}$ / haploview). Bonferroni multiple comparison correction method was employed in calculating the corrected $\mathrm{P}(\mathrm{Pc})$ value: $\mathrm{Pc}=1-(1-\mathrm{P}) n$, where $n=$ number of comparisons. Logistic regression analysis was performed to determine odds ratios (OR) and $95 \%$ confidence intervals $(95 \% \mathrm{CI})$ associated with OC risk, taking the control women as the reference group. Statistical significance was set at $p<0.05$.

\section{Results}

\section{Study subjects}

Demographic and clinical characteristics of cases and controls are described in Table 1. Median age was 51 years. Among OC patients, 36 (50.70\%) were older than 50 years and $43(60.60 \%)$ were post-menopausal. Diagnoses of OC confirmed by histology according to FIGO revealed 10 patients $(14.10 \%)$ with stage I, $25(35.20 \%)$ with stage II, $30(42.30 \%)$ with stage III, and 6 cases $(8.50 \%)$ with stage IV. The majority of histological types found included serious papillary cell carcinoma (49 patients, $69.00 \%$ ), followed by endometrioid (14 cases, $19.70 \%$ ), mixed/others (7, 9.90\%), and mucinous (1 patient, 1.40\%).

\section{$T G F-\beta 1$ and $I L-6$ alleles and genotype distribution}

The allelic distribution of three TGF- $\beta 1$ and eight IL-6 SNPs between OC patients and controls are summarized in Table 2 . Our results showed only a negative significantly association between the minor allele of IL-6 rs 1880242 and OC susceptibility $(p=0.0275$; OR $[95 \% \mathrm{CI}]=0.53$ [0.29-0.97]).

At genotypic level, comparing to $\mathrm{C} / \mathrm{C}$ genotype of TGF- $\beta 1$ rs 1800469 , the frequencies of C/T genotype were significantly lower in $\mathrm{OC}$ cases in under additive $(p<0.001$; OR [95\% CI] $=0.24$ [0.15-0.58] $)$ and dominant $(p<0.001$, OR [95\% CI] $=0.33$ [0.15-0.74]) genetic models (Table 3). The genotype distributions of tested IL-6 variants, taking homozygous wild-type genotype as a reference $(\mathrm{OR}=1.00)$, demonstrated that the combined genotypes of IL- 6 rs1880242 [G/T+T/T] decreased the risk of OC $(p=0.021 ;$ OR [95\% CI] $=0.38$ [0.17-0.88]) (Table 4).

\section{TGF- $\beta 1$ and IL-6 haplotypes distribution}

Table 5 presents the frequencies of three-locus TGF- $\beta 1$ haplotypes in OC cases and controls, constructed based on the prevalence of individual SNPs and linkage disequilibrium (LD) between them. Of the 8 possible haplotypes, six were found to be common and were included in the anal-
Table 1. Characteristics of the study participants

\begin{tabular}{lccc}
\hline Characteristics & $\begin{array}{c}\text { Cases } \\
(n=71)\end{array}$ & $\begin{array}{c}\text { Controls } \\
(n=74)\end{array}$ & $p$-value* \\
\hline
\end{tabular}

Environmental characteristics

\begin{tabular}{lccc}
\hline Age $($ mean $\pm \mathrm{SD})$ & $51.08 \pm 14.04$ & $51.73 \pm 14.21$ & 0.584 \\
\hline$\geq 50$ years, $n(\%)$ & $36(50.70)$ & $39(52.70)$ & 0.470 \\
\hline Post-menopausal, $n(\%)$ & $43(60.60)$ & $47(63.50)$ & 0.422 \\
\hline Clinical characteristics & & &
\end{tabular}

FIGO staging of cancer, $n(\%)$

\begin{tabular}{lll}
\hline Stage I & $10(14.10)$ & N/A \\
\hline Stage II & $25(35.20)$ & N/A \\
\hline Stage III & $30(42.30)$ & N/A \\
\hline Stage IV & $06(08.50)$ & N/A \\
\hline Histological type, $n(\%)$ & & \\
\hline Serious papillary & $49(69.00)$ & N/A \\
\hline Endometrioid & $14(19.70)$ & N/A \\
\hline Mixed/other & $07(09.90)$ & N/A \\
\hline Mucinous & $01(01.40)$ & N/A
\end{tabular}

$\overline{F I G O \text { - International Federation of Gynecology and Obstetrics, NA - not }}$ applicable, * Student's t-test (continuous variables), Pearson $\chi^{2}$ test (categorical variables)

ysis. Strong LD was found between TGF- $\beta 1$ rs1800470, TGF- $\beta 1$ rs 1800472, and TGF- $\beta 1$ rs1800469 (D', 0.889; LOD, 4.28; $r^{2}, 0.093$ ) (Fig. 1). Haplotype analysis showed that the distribution of TGF- $\beta 1$ haplotypes was comparable between OC cases and control women, but not significant association was observed (Table 5).

Furthermore, we evaluated the interaction between the tested IL-6 single nucleotide polymorphisms and by analyzing the haplotype distribution of 8-locus (IL-6 rs1880242, IL-6 rs2069827, IL-6 rs1800797, IL-6 rs1800796, IL-6 rs1800795, IL-6 rs1474348, IL-6 rs1474347, and IL-6 rs2069845) in OC cases and healthy controls by Haploview. Haplotype analysis demonstrated strong LD between IL-6 SNPs (Fig. 2).

Results from Table 6 demonstrated development of GGAGGGGA and GGAGGGTA haplotypes and reduction in TGGGCCTA haplotype among OC cases than controls, thus conferring disease risk and protection to these IL-6 haplotypes, respectively. The distribution of other haplotypes was comparable between OC cases and control subjects.

\section{Discussion}

The exact mechanism causing the pathogenesis and increased susceptibility to OC remain unclear and controversial. It was previously suggested that chronic inflammatory changes are associated with the development and 
Table 2. TGF- $\beta 1$ and IL-6 SNPs allelic distribution in patients and controls

\begin{tabular}{|c|c|c|c|c|c|c|c|c|}
\hline \multicolumn{3}{|c|}{ SNPs } & \multicolumn{2}{|c|}{ MAF } & \multirow[t]{2}{*}{ HWE } & \multirow[t]{2}{*}{$\chi^{2}$} & \multirow[t]{2}{*}{$p$-value } & \multirow[t]{2}{*}{ OR $(95 \% \mathrm{CI})$} \\
\hline rs number & Location $^{\mathrm{a}}$ & MA & Cases $^{b}$ & Controls $^{\mathbf{b}}$ & & & & \\
\hline \multicolumn{9}{|l|}{ TGF- $\beta 1$} \\
\hline rs1800472 & 41341955 & $\mathrm{~T}$ & 0.06 & 0.06 & 0.23 & 0.02 & 0.87 & $1.08(0.40-2.89)$ \\
\hline rs 1800470 & 41353016 & $\mathrm{C}$ & 0.37 & 0.33 & 0.06 & 0.56 & 0.45 & $1.20(0.74-1.94)$ \\
\hline rs1800469 & 41354391 & $\mathrm{~T}$ & 0.30 & 0.39 & 0.46 & 2.17 & 0.14 & $1.44(0.88-2.34)$ \\
\hline \multicolumn{9}{|l|}{ IL-6 } \\
\hline rs1880242 & 22719988 & $\mathrm{~T}$ & 0.170 & 0.280 & 0.1195 & 4.862 & 0.0275 & $0.53(0.29-0.97)$ \\
\hline rs2069827 & 22725837 & $\mathrm{~T}$ & 0.035 & 0.027 & 1.0 & 0.161 & 0.6879 & $1.31(0.30-5.96)$ \\
\hline rs1800797 & 22726602 & G & 0.150 & 0.160 & 0.1939 & 0.113 & 0.7372 & $0.90(0.45-1.77)$ \\
\hline rs1800796 & 22726627 & $\mathrm{C}$ & 0.080 & 0.080 & 0.4262 & 0.013 & 0.9093 & $0.95(0.38-2.44)$ \\
\hline rs1800795 & 22727026 & $\mathrm{C}$ & 0.130 & 0.160 & 0.1026 & 0.273 & 0.6013 & $0.84(0.41-1.70)$ \\
\hline rs 1474348 & 22728289 & $\mathrm{C}$ & 0.180 & 0.190 & 0.0027 & 0.084 & 0.7724 & $0.92(0.48-1.73)$ \\
\hline rs1474347 & 22728505 & $\mathrm{~T}$ & 0.170 & 0.180 & 0.0667 & 0.023 & 0.8807 & $0.95(0.50-1.83)$ \\
\hline rs2069845 & 22730530 & A & 0.283 & 0.203 & 0.0554 & 2.491 & 0.1145 & $1.55(0.87-2.77)$ \\
\hline
\end{tabular}

Table 3. TGF- $\beta 1$ genotype distribution in cases and controls

\begin{tabular}{|c|c|c|c|c|c|}
\hline SNP & Genotypes & Casesa & Controlsa & $p$-value & OR $(95 \% \mathrm{CI})$ \\
\hline \multirow[t]{4}{*}{ rs 1800472} & $\mathrm{C} / \mathrm{C}$ & $63(88.70 \%)$ & $66(89.20 \%)$ & \multirow[t]{3}{*}{0.42} & 1.00 (ref.) \\
\hline & $\mathrm{C} / \mathrm{T}$ & $08(11.30 \%)$ & $07(09.50 \%)$ & & $1.34(0.38-4.80)$ \\
\hline & $\mathrm{T} / \mathrm{T}$ & $00(00.00 \%)$ & $01(01.40 \%)$ & & 0.00 (0.00-ND) \\
\hline & {$[\mathrm{C} / \mathrm{T}+\mathrm{T} / \mathrm{T}]$} & $08(11.30 \%)$ & $08(10.80 \%)$ & 0.42 & $1.15(0.33-3.95)$ \\
\hline \multirow[t]{4}{*}{ rs 1800470} & $\mathrm{~T} / \mathrm{T}$ & $33(47.90 \%)$ & $37(50.00 \%)$ & \multirow[t]{3}{*}{0.54} & 1.00 (ref.) \\
\hline & $\mathrm{T} / \mathrm{C}$ & $21(29.60 \%)$ & $25(33.60 \%)$ & & $0.98(0.39-2.45)$ \\
\hline & $\mathrm{C} / \mathrm{C}$ & $16(22.50 \%)$ & $12(16.20 \%)$ & & $1.69(0.59-4.89)$ \\
\hline & {$[\mathrm{T} / \mathrm{C}+\mathrm{C} / \mathrm{C}]$} & $37(52.10 \%)$ & $37(50.00 \%)$ & 0.66 & $1.20(0.53-2.73)$ \\
\hline \multirow[t]{4}{*}{ rs1800469 } & $\mathrm{C} / \mathrm{C}$ & $40(56.30 \%)$ & $26(35.10 \%)$ & \multirow[t]{3}{*}{$<0.001$} & 1.00 (ref.) \\
\hline & $\mathrm{C} / \mathrm{T}$ & $19(26.80 \%)$ & $39(52.70 \%)$ & & $0.24(0.1-0.58)$ \\
\hline & $\mathrm{T} / \mathrm{T}$ & $12(16.90 \%)$ & $09(12.20 \%)$ & & $0.81(0.25-2.65)$ \\
\hline & {$[\mathrm{C} / \mathrm{T}+\mathrm{T} / \mathrm{T}]$} & $31(43.70 \%)$ & $48(64.90 \%)$ & $<0.001$ & $0.33(0.15-0.74)$ \\
\hline
\end{tabular}

Values in bold are statistically significant at the $5 \%$ level, ${ }^{a}$ study subjects comprised 71 ovarian cancer patients and 74 control women, ND - not defined, OR - odds ratio; nominal value of comparison, $p>0.05$, no significant association, degree of freedom $=1$

clinical course of OC [14]. In this regard, a central role of cytokines in cancer immunity was proposed, and it was originally suggested that altered expression of Th1-Th2 facilitates tumor growth through precipitation of initial state of tumor-specific and later, antigen non-specific immunosuppression (anergy) [15]. Recently, Th17 and Treg cells were described as key factors in regulating tumor growth. TGF- $\beta 1$ is a multifunctional cytokine, which regulates the production of extracellular matrix, neovascularization, and immune response. Additionally, it promotes normal cell differentiation and motility, and is a crucial element in early stage of cancer [39, 40]. Owing to its action as angiogenic factor, TGF- $\beta 1$ contributes to the pathology of advanced tumor stages, and is essential for the development, growth, invasion, and metastasis of cancer [41-43]. IL-6 has been previously known as hepatocyte-stimulating factor, cytotoxic T-cell differentiation factor, B-cell differentiation factor, B-cell stimulatory factor 2, hybridoma/ plasmacytoma growth factor, monocyte granulocyte inducer type 2, and thrombopoietin, reflecting pleiotropism of this cytokine and its involvement in numerous biological functions [44-46]. 
Table 4. IL-6 genotype distribution in cases and controls

\begin{tabular}{|c|c|c|c|c|c|}
\hline SNP & Genotypes & Casesa & Controlsa & $p$-value & OR $(95 \%$ CI $)$ \\
\hline \multirow[t]{4}{*}{ rs 1880242} & $\mathrm{G} / \mathrm{G}$ & $50(70.4 \%)$ & $41(55.4 \%)$ & \multirow[t]{3}{*}{0.053} & 1.00 (ref.) \\
\hline & $\mathrm{G} / \mathrm{T}$ & $18(25.4 \%)$ & $25(33.8 \%)$ & & $0.43(0.18-1.05)$ \\
\hline & $\mathrm{T} / \mathrm{T}$ & $03(04.2 \%)$ & $08(10.8 \%)$ & & $0.23(0.04-1.17)$ \\
\hline & {$[\mathrm{G} / \mathrm{T}+\mathrm{T} / \mathrm{T}]$} & $21(29.6 \%)$ & $33(44.6 \%)$ & 0.021 & $0.38(0.17-0.88)$ \\
\hline \multirow[t]{4}{*}{ rs2069827 } & $\mathrm{G} / \mathrm{G}$ & $66(93.0 \%)$ & $70(94.6 \%)$ & \multirow[t]{3}{*}{0.690} & 1.00 (ref.) \\
\hline & $\mathrm{G} / \mathrm{T}$ & $04(05.4 \%)$ & $05(07.0 \%)$ & & $1.38(0.28-6.78)$ \\
\hline & $\mathrm{T} / \mathrm{T}$ & 0 & 0 & & ND \\
\hline & {$[\mathrm{G} / \mathrm{T}+\mathrm{T} / \mathrm{T}]$} & - & - & & ND \\
\hline \multirow[t]{4}{*}{ rs 1800797} & $\mathrm{~A} / \mathrm{A}$ & $52(73.2 \%)$ & $54(73.0 \%)$ & \multirow[t]{3}{*}{0.900} & 1.00 (ref.) \\
\hline & $\mathrm{A} / \mathrm{G}$ & $17(23.9 \%)$ & $16(21.6 \%)$ & & $1.10(0.42-2.88)$ \\
\hline & $\mathrm{G} / \mathrm{G}$ & $02(02.8 \%)$ & $04(05.4 \%)$ & & $0.68(0.10-4.80)$ \\
\hline & {$[\mathrm{A} / \mathrm{G}+\mathrm{G} / \mathrm{G}]$} & $19(26.8 \%)$ & $20(27.0 \%)$ & 0.980 & $1.01(0.42-2.45)$ \\
\hline \multirow[t]{4}{*}{ rs1800796 } & $\mathrm{G} / \mathrm{G}$ & $60(84.5 \%)$ & $64(86.5 \%)$ & 0.045 & 1.00 (ref.) \\
\hline & $\mathrm{G} / \mathrm{C}$ & $11(15.5 \%)$ & $08(10.8 \%)$ & \multirow{3}{*}{0.620} & $1.65(0.51-5.03)$ \\
\hline & $\mathrm{C} / \mathrm{C}$ & 0 & $02(02.7 \%)$ & & ND \\
\hline & {$[\mathrm{G} / \mathrm{C}+\mathrm{C} / \mathrm{C}]$} & $64(86.5 \%)$ & $10(13.5 \%)$ & & $1.33(0.42-4.06)$ \\
\hline \multirow[t]{4}{*}{ rs 1800795} & $\mathrm{G} / \mathrm{G}$ & $54(76.1 \%)$ & $55(74.3 \%)$ & \multirow[t]{3}{*}{0.920} & 1.00 (ref.) \\
\hline & $\mathrm{G} / \mathrm{C}$ & $15(21.1 \%)$ & $15(20.3 \%)$ & & $0.98(0.37-2.61)$ \\
\hline & $\mathrm{C} / \mathrm{C}$ & $02(02.8 \%)$ & $04(05.4 \%)$ & & $0.61(0.09-4.70)$ \\
\hline & {$[\mathrm{G} / \mathrm{C}+\mathrm{C} / \mathrm{C}]$} & $19(25.7 \%)$ & $17(23.9 \%)$ & 0.840 & $0.91(0.38-2.23)$ \\
\hline \multirow[t]{4}{*}{ rs1474348 } & $\mathrm{G} / \mathrm{G}$ & $50(70.4 \%)$ & $53(71.6 \%)$ & \multirow[t]{3}{*}{0.630} & 1.00 (ref.) \\
\hline & $\mathrm{G} / \mathrm{C}$ & $17(23.9 \%)$ & $14(18.9 \%)$ & & $1.40(0.52-3.77)$ \\
\hline & $\mathrm{C} / \mathrm{C}$ & $04(05.6 \%)$ & $07(09.5 \%)$ & & $0.66(0.16-2.80)$ \\
\hline & {$[\mathrm{G} / \mathrm{C}+\mathrm{C} / \mathrm{C}]$} & $21(29.6 \%)$ & $21(28.4 \%)$ & 0.80 & $1.12(0.47-2.67)$ \\
\hline \multirow[t]{4}{*}{ rs 1474347} & $\mathrm{G} / \mathrm{G}$ & $50(70.4 \%)$ & $53(71.6 \%)$ & \multirow[t]{3}{*}{0.81} & 1.00 (ref.) \\
\hline & $\mathrm{G} / \mathrm{T}$ & $18(25.4 \%)$ & $16(21.6 \%)$ & & $1.23(0.46-3.29)$ \\
\hline & $\mathrm{T} / \mathrm{T}$ & $03(04.2 \%)$ & $05(06.8 \%)$ & & $0.69(0.13-3.79)$ \\
\hline & {$[\mathrm{G} / \mathrm{T}+\mathrm{T} / \mathrm{T}]$} & $21(29.6 \%)$ & $21(28.4 \%)$ & 0.86 & $1.09(0.44-2.67)$ \\
\hline \multirow[t]{4}{*}{ rs2069845 } & $\mathrm{G} / \mathrm{G}$ & $38(55.1 \%)$ & $49(66.2 \%)$ & \multirow[t]{3}{*}{0.23} & 1.00 (ref.) \\
\hline & $\mathrm{G} / \mathrm{A}$ & $23(33.3 \%)$ & $20(27.0 \%)$ & & $1.65(0.65-4.17)$ \\
\hline & $\mathrm{A} / \mathrm{A}$ & $08(11.6 \%)$ & $05(06.8 \%)$ & & $2.89(0.75-11.23)$ \\
\hline & {$[\mathrm{G} / \mathrm{A}+\mathrm{A} / \mathrm{A}]$} & $31(44.9 \%)$ & $25(33.8 \%)$ & 0.12 & $1.93(0.83-4.45)$ \\
\hline
\end{tabular}

Values in bold are statistically significant at the 5\% level, a study subjects comprised 71 ovarian cancer patients and 74 control women, ND - not defined, $O R$ - odds ratio; nominal value of comparison, $p>0.05$, no significant association, degree of freedom $=1$

It was established that IL-6 affects practically every organ, most notably the immune system. The physiological activity of IL-6 is very complex, including both pro-inflammatory and anti-inflammatory effects. This combination suggests that IL-6 may play a role in the control of immune system activation during various phases of epithelial ovarian cancer evolution [14, 47, 48].

In this study, we investigated the association of three TGF- $\beta 1$ polymorphisms (rs1800469, rs1800470, and rs1800472) and eight IL-6 SNPs (rs1880242, rs2069827, rs1800797 rs1800796, rs1800795, rs1474348, rs1474347, and rs2069845) with the susceptibility to OC in Tunisians, the first to examine the possible association with $\mathrm{OC}$ in North African community.

Data obtained indicated that TGF- $\beta 1$ rs1800469 heterozygosity was associated with a significant decrease in the risk of $\mathrm{OC}$, thus assigning an $\mathrm{OC}$ protective nature for this variant. Previously, it was reported that carriage of the 
Table 5. Distribution of 3-locus TGF- $\beta 1$ haplotypes in ovarian cancer (OC) cases and controls

\begin{tabular}{lccccc}
\hline Haplotype $^{\mathrm{a}}$ & Frequency & OC cases & Controls & Pc & aOR (95\% CI) \\
\hline CTC & 0.537 & 0.541 & 0.537 & - & $1.00($ ref. $)$ \\
\hline CCT & 0.220 & 0.248 & 0.205 & 0.64 & $0.87(0.50-1.53)$ \\
\hline CCC & 0.113 & 0.062 & 0.152 & 0.11 & $1.87(0.86-4.04)$ \\
\hline CTT & 0.069 & 0.086 & 0.048 & 0.26 & $0.56(0.20-1.54)$ \\
\hline TTT & 0.037 & 0.040 & 0.034 & 1.00 & $1.00(0.31-3.24)$ \\
\hline TCT & 0.017 & 0.009 & 0.014 & 0.60 & $0.61(0.09-3.97)$ \\
\hline
\end{tabular}

${ }^{a}$ rs 1800472/rs1800470/rs1800469 haplotypes, Pc - corrected p-value according to Bonferroni correction, aOR-adjusted OR controlled from age; bold characters indicate minor allele
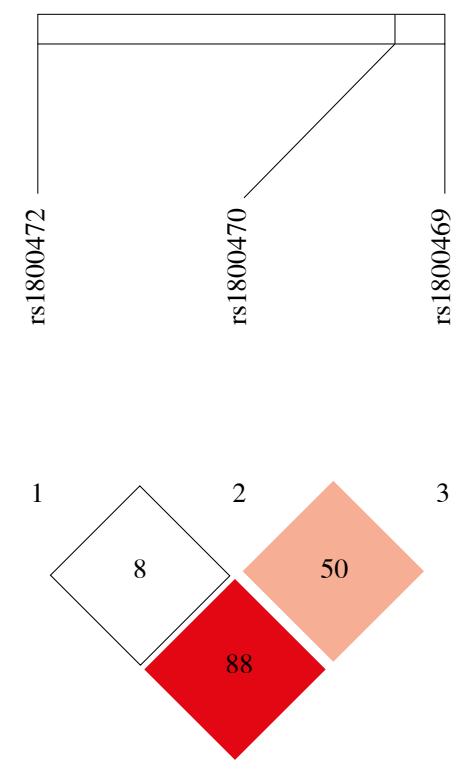

Fig. 1. Linkage disequilibrium (LD) plot and SNPs of TGF- $\beta 1$. The plot was generated using Haploview program with D' color scheme ( $\left.D^{\prime}=0,0\right)$

Table 6. Distribution of 8-locus IL-6 haplotypes in OC cases and controls

\begin{tabular}{|c|c|c|c|c|}
\hline Haplotype $^{\text {a }}$ & Cases & Controls & $\chi^{2}$ & $p$-value \\
\hline GGAGGGGG & 0.581 & 0.641 & 1.113 & 0.2915 \\
\hline TGGGCCTA & 0.063 & 0.135 & 4.129 & 0.0422 \\
\hline GGAGGGGA & 0.102 & 0.034 & 5.338 & 0.0209 \\
\hline TGACGGGG & 0.042 & 0.081 & 1.871 & 0.1714 \\
\hline GGAGGCGG & 0.050 & 0.027 & 0.993 & 0.3191 \\
\hline TGAGGGGG & 0.014 & 0.034 & 1.216 & 0.2701 \\
\hline TTGGCCTA & 0.014 & 0.020 & 0.164 & 0.6858 \\
\hline GGAGGGTA & 0.034 & 0.000 & 5.159 & 0.0231 \\
\hline TGGGCGTA & 0.021 & 0.000 & 2.989 & 0.0838 \\
\hline
\end{tabular}

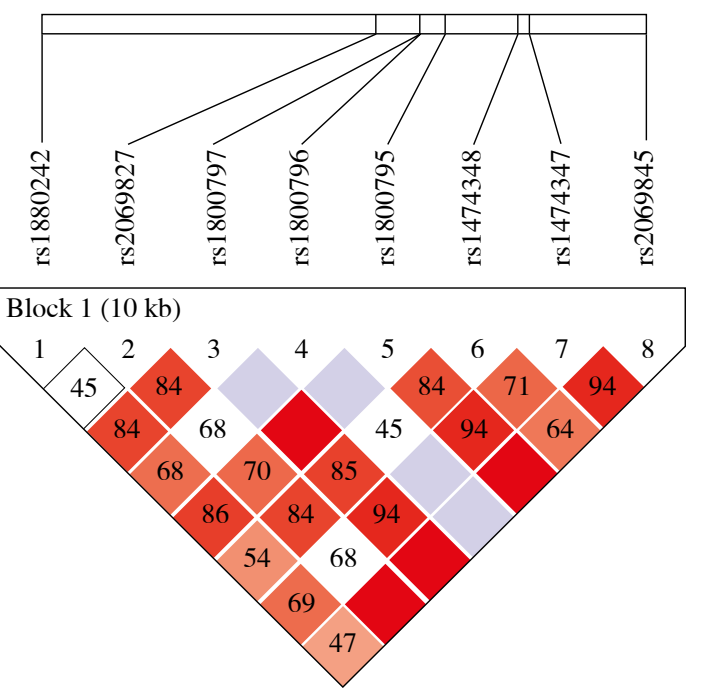

Fig. 2. Linkage disequilibrium (LD) map of the six IL-6 SNPs genotyped using Haploview. The positions of tested SNPs are indicated above the Haploview output. The LD between specific pair of IL-6 SNPs is indicated by color scheme, which represents LD relationships, based on D' values (normalized linkage disequilibrium measure or D) multiplied by 100 . D' is calculated as D divided by theoretical maximum for observed allele frequencies. Values approaching zero indicate absence of LD, and those approaching 100 indicate complete LD. The square-colored red represents varying degrees of LD $<1$ and LOD (logarithm of odds) $>2$ scores; darker shades indicating stronger LD

TGF- $\beta 1$ rs 1800469 minor allele, both in the heterozygous $(\mathrm{C} / \mathrm{T})$ and homozygous (T/T) states, did not affect the susceptibility to OC in Chinese population [49]. In contrast, a recent meta-analysis study that investigated the association between the TGF- $\beta 1$ rs 1800469 and cancers in different ethnic populations concluded that the TGF- $\beta 1$ rs 1800469 minor ( $\mathrm{T}$ ) allele is associated with a decreased risk of colorectal cancer, especially in Caucasians $[50,51]$. These discrepancies may be reconciled by differences in ethnic origin between our Tunisian population and Asian women. 
A possible association between the TGF- $\beta 1$ rs 1800469 and the risk of cancers yielded controversial results, in part due to the type of cancer and ethnic background of study participants [50-57]. Functionally, the TGF- $\beta 1$ promoter variant rs $1800469(-509 \mathrm{C} / \mathrm{T})$ was associated with altered TGF- $\beta 1$ plasma level and emphasized by the almost double level of circulating TGF- $\beta 1$ in heterozygous $(\mathrm{C} / \mathrm{T})$ and homozygous $(\mathrm{T} / \mathrm{T})$ as compared to homozygous $(\mathrm{C} / \mathrm{C})$ genotype carriers [58]. Furthermore, it was previously shown that TGF- $\beta 1$ is over-expressed in some human carcinomas, but not in all types of cancer, and that TGF- $\beta 1$ mutations could influence its implication in cancer development [51, 58].

Heterozygosity of TGF- $\beta 1$ rs 1800469 and the presence of minor allele was associated with protection against OC in the study population. This was in agreement with a recent study, which documented association of TGF- $\beta 1$ rs1800469 with a decreased risk of breast cancer in American women of African and European ancestry [54]. Neither TGF- $\beta 1$ rs 1800470 or TGF- $\beta 1$ rs 1800472 were markedly associated with $\mathrm{OC}$ in Tunisian women. This was the first report that examined the association between TGF- $\beta 1$ variants and OC risk in Tunisia and worldwide. Previous studies examined the possible influence of genetic mutations in ovarian neoplasia and showed that TGF- $\beta 1$ gene variants may influence (multistage) ovarian neoplasia by reducing epithelial cell responsiveness to TGF- $\beta 1$ negative growth signals $[23,24]$.

For IL-6 gene polymorphisms, our results showed that only IL-6 rs 1880242 was implicated in the occurrence of $\mathrm{OC}$ in Tunisia. Therefore, minor allele frequency (MAF) was considered as a risk factor, and the combined genotypes decreased the incidence of OC. The present study is the first to suggest a protective role of IL-6 rs1880242 in OC susceptibility. In fact, in Malaysian population, this SNP increased the risk to OC development [59]. These contradictory results for IL-6 rs 1880242 and OC risk between Tunisians and Malaysians could be generated by the geographic and ethnical origin of populations, thus leading to the discordant findings between this polymorphism and OC occurrence. On the other hand, our data showed that IL-6 allele and genotype frequencies between OC cases with early tumor stages and healthy controls were comparable, but no significant association was detected between the seven IL-6 SNPs. In agreement with our results, previous study on Chinese population has reported a lack of association between IL-6 rs1800795 and OC risk [60].

It was established that IL-6 rs1800795 was associated with the plasma levels of protein [61]. However, some studies have investigated the possible association between this SNP, IL-6 plasma levels, and risk of cancers with controversial results [62-67].

In Tunisia, few case-control studies were conducted to evaluate the impact of IL-6 polymorphisms and cancers. A study by Snoussi et al. showed a significant association between SNPs in the promoter region IL-6 rs1800795 and
IL-6 rs1800797 with breast cancer risk [68]. However, in our present study, we concluded that IL-6 rs1800795 and IL-6 rs1474348 were associated with cervical cancer susceptibility and evolution among Tunisian women [31].

On the other hand, our study suggests an association between IL-6 haplotypes (GGAGGGGA, GGAGGGTA and TGGGCCTA) and OC occurrence. To the best of our knowledge, no previous haplotypes association was detected between those eight IL-6 SNPs and OC susceptibility.

The present study has some strengths, including OC cases and control women of similar ethnicity, thus minimizing the possibility of admixture, and that only new OC cases prior to chemo- or radiotherapy were recruited. However, our studies had also some limitations, mostly due to the relatively limited sample size. Despite the incidence of OC in Tunisia, the rareness of this pathology lies in its quiet character responsible for a delay in diagnosis and therapeutic difficulty, especially in its extended forms. Therefore, the low sample size cannot lower the power of our study.

\section{Conclusions}

In the summary, this is the first study to show an association of TGF- $\beta 1$ and IL-6 SNPs implicated in the inflammatory cascade with $\mathrm{OC}$ occurrence. We conclude that the TGF- $\beta 1$ rs1800469, IL-6 rs1880242, and the IL-6 haplotype distribution may contribute to the occurrence of OC among Tunisian women. Subsequently, future studies will be performed to better understand the mechanism of TGF- $\beta 1$ and IL- 6 polymorphism involvement in changed plasma levels of these two proteins and their potential impact on OC.

The authors declare no conflict of interest.

\section{References}

1. Ferlay J, Soerjomataram I, Dikshit R, et al. (2015): Cancer incidence and mortality worldwide: sources, methods and major patterns in GLOBOCAN 2012. Int J Cancer 136: 359-386.

2. Bray F, Ferlay J, Laversanne M, et al. (2014): Cancer Incidence in Five Continents: Inclusion criteria, highlights from Volume $\mathrm{X}$ and the global status of cancer registration. Int J Cancer 137: 2060-2071.

3. Lengyle E (2010): Ovarian cancer development and metastasis. Am J Pathol 177: 1053-1064.

4. Brucks JA (1992): Ovarian cancer. The most lethal gynecologic malignancy. Nurs Clin North Am 27: 835-845.

5. Schrecengost A (2002): Ovarian mass- benign or malignant? AORN J 76: 792-802.

6. Eiro' N, Vizoso FJ (2012): Inflammation and cancer. World J Gastrointest Surg 4: 62-72.

7. Phoa N, Epe B (2002): Influence of nitric oxide on the generation and repair of oxidative DNA damage in mammalian cells. Carcinogenesis 23: 469-475. 
8. Culig Z, Steiner H, Bartsch G, Hobisch A (2005): Interleukin-6 regulation of prostate cancer cell growth. J Cell Biochem 95: 497-505.

9. Gulden C, Olopade OI (2010): Risk assessment and genetic testing for ovarian cancer. AJR Am. J. Roentgenol 194: 309310.

10. Balmain A, Gray J, Ponder B (2003): The genetics and genomics of cancer. Nat Genet 33: 238-244.

11. Kotnis A, Sarin R, Mulherkar R (2005): Genotype, phenotype and Cancer: role of low penetrance genes and environment in tumour susceptibility. J Biosci 30: 93-102.

12. Kulbe H, Chakravarty P, Leinster DA, et al. (2012): A dynamic inflammatory cytokine network in the human ovarian cancer microenvironment. Cancer Res 72: 66-75.

13. Matte I, Lane D, Laplante C, et al. (2012): Profiling of cytokines in human epithelial ovarian cancer ascites. Am J Cancer Res 2: 566-580.

14. Macciň A, Madeddu C (2012): Inflammation and ovarian cancer. Cytokine 58: 133-147.

15. Balkwill F, Mantovani A (2001): Inflammation and cancer: Back to Virchow? Lancet 357: 539-545.

16. Grainger DJ (2004): Transforming growth factor beta and atherosclerosis: so far, so good for the protective cytokine hypothesis. Arterioscler Thromb Vasc Biol 24: 399-404.

17. Massagué J, Blain SW, Lo RS (2000): TGF beta signaling in growth control, cancer, and heritable disorders. Cell 103: 295-309.

18. Derynck R, Akhurst RJ, Balmain A (2001): TGF-beta signaling in tumor suppression and cancer progression. Nat Genet 29: 117-129.

19. De Caestecker MP, Piek E, Roberts AB (2000): Role of transforming growth factor-beta signaling in cancer. J Natl Cancer Inst 92: 1388-1402.

20. Reiss M (1999): TGF-beta and cancer. Microbes Infect 1: 1327-1347.

21. Polyak K (1996): Negative regulation of cell growth by TGF $\beta$. Biochim Biophys Acta 1242: 185-199.

22. Yin J, Lu K, Lin J, et al. (2011): Genetic variants in TGF- $\beta$ pathway are associated with ovarian cancer risk. PLoS One 6: e25559.

23. Cardillo MR, Yap E, Castagna G (1997): Molecular genetic analysis of TGF-beta1 in ovarian neoplasia. J Exp Clin Cancer Res 16: 49-56.

24. Francis-Thickpenny, Richardson DM, Van Ee CC, et al. (2001): Analysis of the TGF beta functional pathway in epithelial ovarian carcinoma. Br J Cancer 85: 687-691.

25. Liu Y, Lin XF, Lin CJ, et al. (2012): Transforming growth factor beta-1 C-509T poymorphism and cancer risk: a meta-analysis of 55 case-control studies. Asian Pac J Cancer Prev 13: 4683-4688.

26. Barton BE, Jackson JV (1993): Protective role of interleukin 6 in the lipopolysaccharide-galactos amine septic shock model. Infect Immun 61: 1496.

27. Bowcock AM, Kidd JR, Lathrop GM, et al. (1988): The human "interferon-beta $2 /$ hepatocyte stimulating factor/interleukin-6" gene: DNA polymorphism studies and localization to chromosome 7p21. Genomics 3: 8-16.

28. Diehl S, Rincon M (2002): The two faces of IL- 6 on Th1/Th2 differentiation. Mol Immunol 39: 531-536.

29. Asschert JG, Vellenga E, Ruiters MH, De Vries EG (1999): Regulation of spontaneous and TNF/IFN-induced IL-6 expression in two human ovarian-carcinoma cell lines. Int J Cancer 82: 244-249.
30. Zhang K, Zhang L, Zhou J, et al. (2016): Association between interleukin-6 polymorphisms and urinary system cancer risk: evidence from a meta-analysis. Onco Targets Ther 9: 567.

31. Zidi S, Stayoussef M, Alsaleh BL, et al. (2016): Relationships between Common and Novel Interleukin-6 Gene Polymorphisms and Risk of Cervical Cancer: a Case-Control Study. Pathol Oncol Res 23: 385-392.

32. Berger FG (2004): The interleukin-6 gene: a susceptibility factor that may contribute to racial and ethnic disparities in breast cancer mortality. Breast Cancer Res Treat 88: 281-285.

33. Yu Y, Wang W, Zhai S, et al. (2012): IL6 gene polymorphisms and susceptibility to colorectal cancer: a meta-analysis and review. Mol Biol Rep 39: 8457-8463.

34. Zheng X, Han C, Shan R, et al. (2015): Association of interleukin-6 polymorphisms with susceptibility to hepatocellular carcinoma. Int J Clin Exp Med 8: 6252-6256.

35. Tjiong MY, van der Vange N, ten Kate FJ, et al. (1999): Increased IL-6 and IL-8 levels in cervicovaginal secretions of patients with cervical cancer. Gynecol Oncol 73: 285-291.

36. Darai E, Detchev R, Hugol D, Quang NT (2003): Serum and cyst fluid levels of interleukin(IL)-6, IL-8 and tumor necrosis factor-alpha in women with endometriomas and benign and malignant cystic ovarian tumors. Hum Reprod 18: 1681-1685.

37. Asschert JG, De Vries EG, De Jong S, et al. (1999): Differential regulation of IL-6 promoter activity in a human ovarian-tumor cell line transfected with various p53 mutants: involvement of AP-1. Int J Cancer 81: 236-242.

38. Watson JM, Sensintaffar JL, Berek JS, Martinez-Maza $\mathrm{O}$ (1990): Constitutive production of interleukin 6 by ovarian cancer cell lines and by primary ovarian tumor cultures. Cancer Res 50: 6959-6965.

39. Massagué J (2008): TGF beta in cancer. Cell 134: 215-230.

40. Liu C, Zhang L, Chang X, et al. (2012): Overexpression and immunosuppressive functions of transforming growth factor 1 , vascular endothelial growth factor and interleukin-10 in epithelial ovarian cancer. Chin J Cancer Res 24: 130-137.

41. Carmeliet P, Jain RK (2000): Angiogenesis in cancer and other diseases. Nature 407: 249-257.

42. Shimo T, Nakanishi T, Nishida T, et al. (2001): Involvement of CTGF, a hypertrophic chondrocyte-specific gene product, in tumor angiogenesis. Oncology 61: 315-322.

43. Roberts AB, Sporn MB, Assoian RK, et al. (1986): Transforming growth factor type beta: rapid induction of fibrosis and angiogenesis in vivo and stimulation of collagen formation in vitro. Proc Natl Acad Sci U S A 83: 4167-4171.

44. Hirano T, Yasukawa K, Harada H, et al (1989): Complementary DNA for a novel human interleukin (BSF-2) that induces B lymphocytes to produce immunoglobulin. Nature 324 : 73-76.

45. Gauldie J, Richards C, Harnish D, et al. (1987): Interferon b2/B cell stimulatory factor type 2 shares identity with monocyte-derived hepatocyte stimulating factor and regulates the major acute phase protein response in liver cells. Proc Nat Acad Sci U S A 84: 7251-7255.

46. Garman RD, Jacobs KA, Clark SC, Raulet DH (1987): B-cellstimulating factor 2 (b2 interferon) functions as a second signal for interleukin 2 production by nature murine T cells. Proc Nat Acad Sci U S A 84: 7629-7633.

47. Macciň A, Lai P, Santona MC, et al. (1998): High serum levels of soluble IL-2 receptor, cytokines, and C reactive protein correlate with impairment of $\mathrm{T}$ cell response in patients with advanced epithelial ovarian cancer. Gynecol Oncol 69: 248252. 
48. Macciň A, Madeddu C, Massa D, et al. (2009): Interleukin-6 and leptin as markers of energy metabolic changes in advanced ovarian cancer patients. J Cell Mol Med 13: 39513959.

49. Wei CL, Wu YG (2008): Association of TGF- $\beta 1$ gene single nucleotide polymorphism with ovarian cancer. Guangdong Med 29: 1369-1371.

50. Xiao Y, Yuan X, Qui H, Li Q (2015): Single-nucleotide polymorphisms of TGF $\beta 1$ and ATM associated with radiation-induced pneumonitis: a prospective cohort study of thoracic cancer patients in China. Int J Clin Exp Med 8: 16403-16413.

51. Liu Y, Lin XF, Lin CJ, et al. (2012): Transforming growth factor beta-1 C-509T poymorphism and cancer risk: a meta-analysis of 55 case-control studies. Asian Pac J Cancer Prev 13: 4683-4688.

52. Fachal L, Gómez-Caamańo A, Sánchez-García M, et al. (2012): TGF $\beta 1$ SNPs and radio-induced toxicity in prostate cancer patients. Radiother Oncol 103: 206-209.

53. Li K, Xia F, Zhang K, et al. (2013): Association of a tgf-b1$509 \mathrm{c} / \mathrm{t}$ polymorphism with gastric cancer risk: a meta-analysis. Ann Hum Genet 77: 1-8.

54. Quan L, Gong Z, Yao S, et al. (2014): Cytokine and cytokine receptor genes of the adaptive immune response are differentially associated with breast cancer risk in American women of African and European ancestry. Int J Cancer 134: 1408-1421.

55. Ma J, Liu YC, Fang Y, et al. (2015): TGF- $\beta 1$ polymorphism $509 \mathrm{C}>\mathrm{T}$ is associated with an increased risk for hepatocellular carcinoma in HCV-infected patients. Genet Mol Res 14: 4461-4468.

56. Wang HB, Song WG, Liu HQ, et al. (2015): Role of TGFB1 polymorphism in the development of metastasic brain tumors in non-small cell lung cancer patients. Genet Mol Res 14: 3545-3550.

57. Xiao Y, Yuan X, Qui H, Li Q (2015): Single-nucleotide polymorphisms of TGF $\beta 1$ and ATM associated with radiation-induced pneumonitis: a prospective cohort study of thoracic cancer patients in China. Int J Clin Exp Med 8: 16403-16413.

58. Gautam KA, Pooja S, Sankhwar SN, et al. (2015) c.29C>T polymorphism in the transforming growth factor- $\beta 1$ (TGFB1) gene correlates with increased risk of urinary bladder cancer. Cytokine 75: 344-348.

59. Velapasamy S, Alex L, Chahil JK, et al. (2013): Influences of Multiple Genetic Polymorphisms on Ovarian Cancer Risk in Malaysia. Genet Test Mol Biomarkers 17: 62-68.

60. Lu ZH, Gu XJ, Shi KZ, et al. (2016): Association between genetic polymorphisms of inflammatory response genes and the risk of ovarian cancer. J Formos Med Assoc 115: 31-37.

61. Fishman D, Faulds G, Jeffery R, et al. (1998): The effect of novel polymorphisms in the interleukin-6 (IL-6) gene on IL-6 transcription and plasma IL-6 levels, and an association with systemic-onset juvenile chronic arthritis. J Clin Investig 102: 1369.

62. Xu B, Niu X-B, Wang Z-D, et al. (2011): IL-6- 174G > C polymorphism and cancer risk: a meta-analysis involving 29,377 cases and 37,739 controls. Mol Biol Rep 38: 25892596.

63. Zhang H, Xu Y, Li L, et al. (2012): The interleukin-6 -174G/ $\mathrm{C}$ polymorphism and prostate cancer risk: a systematic review and meta-analysis. Urol Int 88: 447-453.

64. Upadhyay R, Jain M, Kumar S, et al. (2008): Association of interleukin-6 $(-174 \mathrm{G}>\mathrm{C})$ promoter polymorphism with risk of squamous cell esophageal cancer and tumor location: an exploratory study. Clin Immunol 128: 199-204.
65. Slattery ML, Curtin K, Sweeney C, et al. (2008): Modifying effects of IL-6 polymorphisms on body size-associated breast cancer risk. Obesity 16: 339-347.

66. Vairaktaris E, Yiannopoulos A, Vylliotis A, et al. (2006): Strong association of interleukin- $6-174 \mathrm{G}>\mathrm{C}$ promoter polymorphism with increased risk of oral cancer. Int J Biol Markers 21: 246-250.

67. Grimm C, Six L, Tomovski C, et al. (2005): A common interleukin-6 promoter polymorphism in patients with vulvar cancer. J Soc Gynecol Investig 12: 617-620.

68. Snoussi K, Strosberg AD, Bouaouina N, et al. (2005): Genetic variation in pro-inflammatory cytokines (interleukin- $1 \beta$, interleukin- $1 \alpha$ and interleukin-6) associated with the aggressive forms, survival, and relapse prediction of breast carcinoma. Eur Cytokine Netw 16: 253-260. 